\title{
Research on Department Project Management Platform
}

\author{
Jun QIAO \\ Wuhan Ship Communication Institute, China, 430070 \\ 1065103858@qq.com
}

\begin{abstract}
Keywords: the project group management, the foreground, the background, the management special, the complex management special, the department project management platform

Abstract. In the process of the department project management, persons need collect the objective project group running data adequately and use the project management technology to analyze and extract the problems to be solved or receive guidance mission issued by the enterprise for the department as to form the management specials. Finally, the department management is refined to control and implement management specials with information technology.
\end{abstract}

\section{Introduction}

Enterprise's departments are the foundation of project operation. They should not only bear the huge group of projects management, which integrates the project plan management, the human resource management, the quality management, the project risk management, and other aspects of content, but also accept the longitudinal guidance of the enterprise for aspects of the department and practice them. The relationship among the various aspects of the department project management is actually mutual fusion and mutual restriction. They form an organic whole. To accomplish the tasks of the department project management, the persons must focus on both the implementation of a single aspect and considering interaction. The persons must balance among various aspects in order to achieve the best effect of the systematic management. There are two ways to produce management specials. One, by the project planning management in the department as the main line, on the implementation of each key nodes around the implementation of the project management, to timely detect and collect data with all kinds of problems in the process of the project implementation, the persons form the management specials. Another, according to the guidance put forward by the enterprise which collects comprehensive national requirements and the enterprise oneself requirements, the persons form the department management specials.

Information is an important resource in project management. It is the foundation of project management. Project managers are to use $80 \%$ of the time on the information collection and processing. Information management refers to the whole management process. In the process the peoples collect, process and input and output information[1].

\section{The Composition of the Department Project Management Platform}

The department project management platform consists of two parts. They are the foreground and the backstage. The foreground processes related content to monitor and perform the daily tasks of department project group. The foreground is divided into two levels. They are the primary level and the spread level. The primary level is responsible for centralized management of the daily work of the project group. It is responsible for identifying problems in the process of the project implementation or receiving enterprise guidance for the department work to form a management special. The archives of the management specials are established and implementation effects of the management specials are tracked. For the complex management specials, the spread level interface has to be designed to decompose and manage the task. The background is a knowledge database. After the tasks of the complex management specials are completed, the related date in the spread level interface will be turned to the background. The background is used to query, retrieval and analysis the management data in order to provide auxiliary decision support about the department 
management. As shown in Fig. 1.

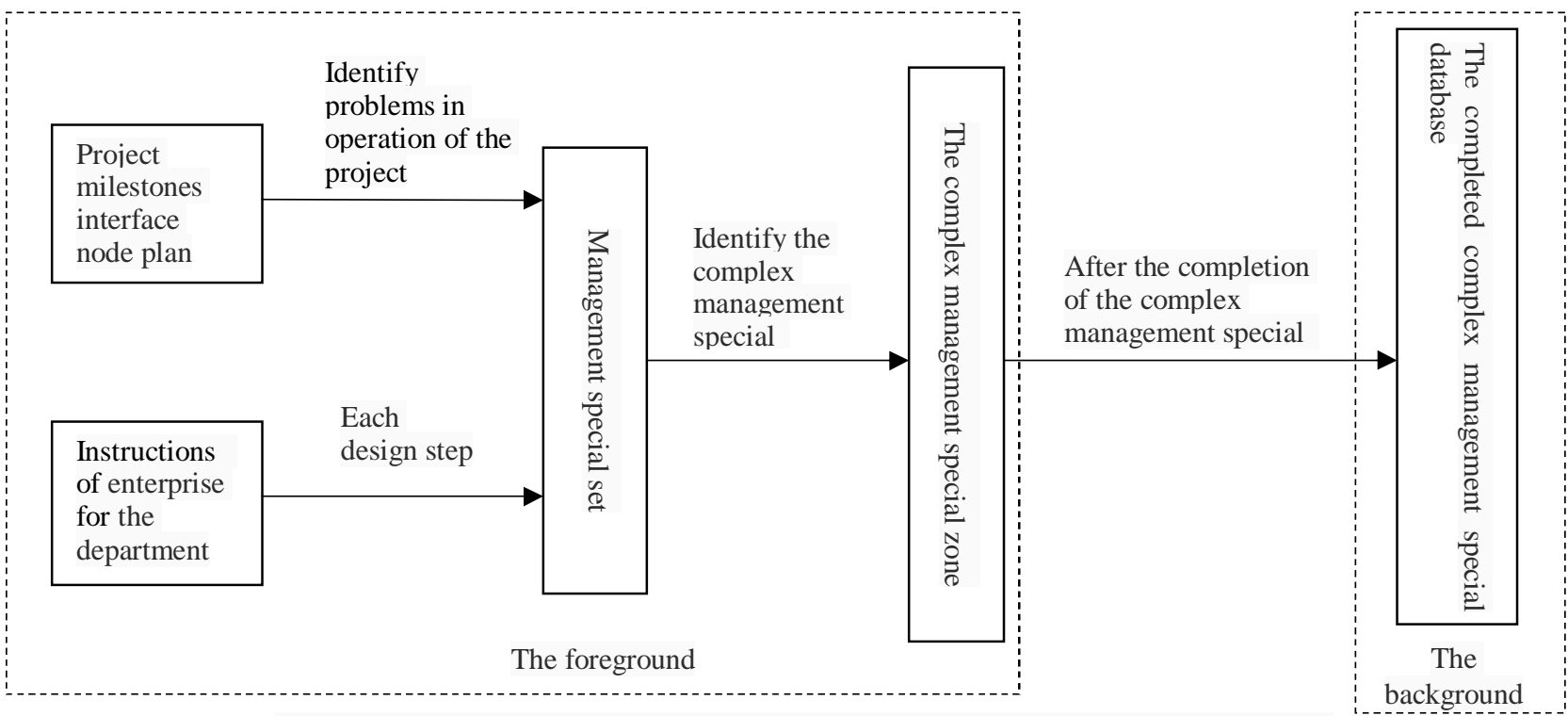

Fig. 1 the Composition of Project Management Platform of Department

\section{The Working Principle of the Department Project Management Platform}

The Foreground. The foreground processes related content to monitor and perform the daily tasks of department project group.

The Operation Interface of Milestone Node Plan of Project Group. For each project the persons set the connotation area and operation area. In the connotation area of the project, the project sequence number, serial number, project name, order quantity, project milestones nodes, security condition matching nodes, engineering team and project leader are showed. These status are given when the project is created. The operation area of project includes this week plan, complement situation, next week plan, project progress, project evaluation, risk assessment, heavy items, project running state, such as content. The operation interface of milestone node plan of project group is a operating tool for the project director to track the performance status of project.

The platform automatically turn last week proposed plan next week operation. According to project milestone nodes and this week plan nodes the project directors check the implementation of the project. At the end of this week, the project directors fill in the progress of the project and make plan for next week. The detailed data of the progress of the project are recorded at the project progress by the end of this week. The key data of the operation of the project will be formed when the project ends. The project directors must compare project milestones node to weekly inspect and examine project running status of this week and judge which the status is "normal" or "risk". For the judgment of risk, risk assessment is presented[2]. The interface also is set the execution state switch. When the project is created the execution state switch is set "doing" state. When the project is completed, the execution state switch will be set "done". The project operation table will be submitted to the department head by the project directors every weekend.

Guidance for the Department from the Enterprise. The guidance of the work for the department from the enterprise is not regularly communicated to the department in email, phone calls, meetings, documents, and other forms. The department head needs to form a management special for the receiving every work instruction and formulates detailed work content and put the management special into the queue collection of management specials so that at time nodes the management special is carried one by one.

The Management Special Interface. The management specials in the management special interface are produced by two ways. One, the persons form the management special with the project operation. The department head is responsible for the weekly summary report of the implementation of the project. He also audits all risks of project. After the risks are confirmed, he has to produces 
related records in the management special interface for them. The risk control plan will be formulated. Another, in accordance with work instruction from the enterprise for the department the department head has to produces the management specials. Each management special is set the task sequence number, name of task, problem/request, start time, finish time, execution status, work schedules, work progress, work category, quarter, problem, etc. There is still the design of the execution state switch. The initial state of new management special is set to the "execution". After the works of the management special are performed and all problems are completely resolved, the state switch of the management special is set to "finish". The management special interface is also designed a "filter" function. It is used to facilitate and analysis the quantity, nature and degree of the risks in the whole life cycle of each project. The department director must identify the complex management special from time to time and build the operation area for the complex management special. At the same time he will link the management special with its area of the complex management special.

The Complex Management Special Zone. The department head needs establish an independent area for each complex management special. This area has an independent name. In the area with task decomposition structure technology each complex management special is carried on the elaboration. This area is designed the flexible management style with its own unique structure decomposition characteristics.

The Background. The background is a database. It saves all operation data about all complex management specials at the closed loop status. It is a portion of the department knowledge management. It is advantageous for the retrieval, query and analysis of the department project management information. The department lead is responsible for the assessment of the operation situation about the complex management special. When identifying the task completed, the execution status of its corresponding management special is set to "finish". At the same time, the complex management special district will be moved to the background[3].

\section{The Application of the Department Project Management Platform}

Solving the Problems of Shortage of Human Resources. According to the mismatch problem between the number of projects and human resources showed on the department project management platform we took measures of the "timely recruitment, fast training and mounting guard, collaboration cross major" to alleviate contradictions. In 2014 we had recruited 7 new department staff. To take the fast train with crash plan, we made timely the new staffs mount guard. And we strengthened the technical training of a multipotent shoulder and carried forward the spirit of collaboration. On the premise of ensuring quality, we did cross major collaboration.

Strict Implementation of the Project Risk Control. In 2014 the project plan risk rate identified by the department was $14 \%$ on average. The implementation of the project risk control was 200 week pieces. The project risk control rate is at $99.79 \%$. For the emergency project we adopt measures to improve the monitoring, priority. There were a total of 329 week pieces. That ensured the implementation of the task of scientific research and production as planned. In 2014 annual plan completion rate was $99.95 \%$.

The Performance about Department Project Management. The department implemented management with the project management platform. And this made the each work of the department ordered and carried out smoothly. In 2014 the department produced 1157 pieces/sets of the equipments. And percent of pass in the factory inspection reached $99.9 \%$. The department participated in the 75 field tests and the technical support tasks. It accomplished the design reasonable and experiment collaboration in place. The each task was completed successfully. It also completed the equipment maintenance task 23 times. And rapid response could be achieved and the person quickly reached the designated position. The faults were accurately positioned. The faults were quickly ruled out. The department implemented the technical training to users 8 times. And the faculties who did stand in the user's point of view implemented lessons seriously with the interactive interpretation. The comprehensive score of after-sales service satisfaction was $99.7 \%$. 
There were not the customer complaints.

We promoted the continuous improvement of product quality. In 2014 we identified 55 quality matters. The department made the files for the quality items one by one. And input into the project management special system for implementation management. According to the quality management process the related works were carried. In 55 we have finished 38. The rest 17 were still going on to succeeded in 2015. Due to the continuing quality improvement of the department, the product quality of the equipment produced by the department steadily was improved.

\section{Conclusions}

With the project management platform we collected and dealt with the management data about the department project group. It effectively supported which the scientific research and the production task were completed. In 2014 we undertook 223 projects about scientific research and production, 95 technical service projects, 5 temporary scientific research and production tasks. The task was total of 323 items. The 355 department management specials were formed in the project management process. In 355 there were the 280 department management specials were produced in the department project operation. It was accounted for $79 \%$. There were the 75 department management specials were produced by which the enterprise guided the department. It was accounted for $21 \%$. In 355 there were the 294 department management specials had be completed, accounted for $83 \%$. The rest of the 41 management specials had be succeeded to continue in 2015, accounted for more than 17\%. In 280 management specials we had identified the 50 complex management specials, accounted for 20\%. And for each complex management special we implemented the refining operation. In 50 there were 32 complex management specials which had been completed, accounted for $64 \%$. And we had removed 32 complex management specials with the complete operation data to the department complex management special database, see tab. 1.

\section{Tab. 1 the Department Project Management Platform Data Distribution}

\begin{tabular}{|c|c|c|c|c|c|c|}
\hline $\begin{array}{c}\text { Serial } \\
\text { number }\end{array}$ & Points & attribute & to deepen & quantity & proportion & of total \\
\hline 1 & \multirow{6}{*}{$\begin{array}{l}\text { Management } \\
\text { special }\end{array}$} & generally & & 285 & $80 \%$ & \multirow[b]{2}{*}{355} \\
\hline 2 & & complex & $\begin{array}{l}\text { building complex } \\
\text { project management } \\
\text { special }\end{array}$ & 50 & $20 \%$ & \\
\hline 3 & & finish & & 294 & $83 \%$ & \multirow{2}{*}{355} \\
\hline 4 & & in & & 41 & $17 \%$ & \\
\hline 5 & & $\begin{array}{l}\text { by the project } \\
\text { operation in } \\
\text { the department }\end{array}$ & & 280 & $79 \%$ & \multirow[t]{2}{*}{355} \\
\hline 6 & & $\begin{array}{l}\text { by the enterprise } \\
\text { guiding }\end{array}$ & & 75 & $21 \%$ & \\
\hline 7 & \multirow[t]{2}{*}{$\begin{array}{l}\text { complex } \\
\text { management } \\
\text { special }\end{array}$} & finish & $\begin{array}{l}\text { to the complex } \\
\text { management special } \\
\text { database in the } \\
\text { background }\end{array}$ & 32 & $64 \%$ & \multirow[t]{2}{*}{50} \\
\hline 8 & & in & & 18 & $36 \%$ & \\
\hline
\end{tabular}

\section{References}

〔1〕Robert C Mahaney, Albert L Lederer. Information systems project management: anagency theory interpretation〔J〕. The Journal of Systems and Software, 2003, (68): 1-9

〔2〕 Thiry M. For DAD: a program management life-cycle process $(\mathbf{J})$. International Journal of 
Project Management , 2004 , 22 ( 3 ): 245-252.

〔3〕 Gui-jun LI, Yue-song ZHANG, From risk management to uncertainty management: a sibnificant change in project management 〔J〕. Journal of Harbin Institute of Technology, 2006,13(3):369-373. 